\title{
Exenatide Exhibits Dose-Dependent Effects on Glycemic Control over 12 Weeks in Japanese Patients with Suboptimally Controlled Type 2 Diabetes
}

\author{
TaKashi KADOWAKI*, Mitsuyoshi NAMBA**, Ayuko YAMAMURA***, Hideaki SOWA***, \\ ANNE M. WOLKA ${ }^{\#}$, ROBERT G. BRODOWS \\ * Department of Metabolic Diseases, Graduate School of Medicine, University of Tokyo, 7-3-1, Hongo, Bunkyo-ku, Tokyo, 113-0033, Japan \\ **Division of Diabetes and Metabolism, Department of Internal Medicine, Hyogo College of Medicine, 1-1 Mukogawa-cho, \\ Nishinomiya Hyogo, 663-8501, Japan \\ ***Lilly Research Laboratories Japan, Eli Lilly Japan KK, Sannomiya Plaza Bldg., 7-1-5, Isogamidori, Chuo-ku, Kobe, 651-0086, Japan \\ ${ }^{\#}$ Lilly Research Laboratories, Eli Lilly and Company, Lilly Corporate Center, Indianapolis, Indiana, 46285, United States
}

\begin{abstract}
This study assessed the dose-dependent efficacy and safety of exenatide over 12 weeks in Japanese patients with type 2 diabetes suboptimally controlled despite therapeutic doses of sulfonylurea (SU), SU plus biguanide, or SU plus thiazolidinedione. Patients were randomly assigned to placebo $(\mathrm{N}=40), 2.5 \mu \mathrm{g}(\mathrm{N}=38), 5 \mu \mathrm{g}(\mathrm{N}=37)$, or $10 \mu \mathrm{g}(\mathrm{N}=38)$ exenatide administered subcutaneously twice daily (BID). Patients randomly assigned to $10 \mu \mathrm{g}$ exenatide received $5 \mu \mathrm{g}$ BID for the first 4 weeks, with the dose escalated to $10 \mu \mathrm{g}$ BID for the final 8 weeks. Patients were $60.3 \pm 9.7$ years old, with body mass index $25.3 \pm 4.3 \mathrm{~kg} / \mathrm{m}^{2}$ and hemoglobin A1c (HbAlc) $8.0 \pm 0.8 \%$. Baseline-to-endpoint HbA1c changes (\%) were $+0.02 \pm 0.1$ (placebo), $-0.9 \pm 0.1(2.5 \mu \mathrm{g}),-1.2 \pm 0.1(5 \mu \mathrm{g})$, and $-1.4 \pm 0.1(10 \mu \mathrm{g})($ all $p<0.001$ vs. placebo). Of patients with baseline $\mathrm{HbAlc} \geq 7 \%, 5.1 \%$ (placebo), 50.0\% (2.5 $\mu \mathrm{g}), 71.4 \%(5 \mu \mathrm{g})$, and 79.4\% (10 $\mu \mathrm{g})$ achieved $\mathrm{HbA1c}$ $<7 \%$ at endpoint $(p<0.001$, trend test). Baseline-to-endpoint fasting plasma glucose changes $(\mathrm{mg} / \mathrm{dL})$ were $+6.0 \pm 4.8$ (placebo), $-18.6 \pm 5.7(2.5 \mu \mathrm{g}),-25.0 \pm 7.0(5 \mu \mathrm{g})$, and $-28.9 \pm 5.9(10 \mu \mathrm{g})($ all $p \leq 0.001 \mathrm{vs}$. placebo). Treatment-emergent adverse events were mostly mild; dose-dependent increases in incidence were observed for hypoglycemia, nausea, anorexia, decreased appetite, and diarrhea (all $\mathrm{p} \leq 0.044$, trend test). Over 12 weeks, exenatide dose-dependently improved glycemic control in Japanese patients with type 2 diabetes.
\end{abstract}

Key words: Exenatide, Dose response, Glycemic control, Japan, Type 2 diabetes

(Endocrine Journal 56: 415-424, 2009)

JAPAN is among the top 10 countries estimated to have had the greatest numbers of people with diabetes in the year 2000 (6.8 million) and is also among the

Received: October 20, 2008

Accepted: January 19, 2009

Correspondence to: Hideaki SOWA, Lilly Research Laboratories Japan, Eli Lilly Japan KK, Sannomiya Plaza Bldg., 7-1-5, Isogamidori, Chuo-ku, Kobe, 651-0086, Japan

Grant support: This study was supported by Amylin Pharmaceuticals, Inc. (San Diego, California, United States) and Eli Lilly and Company (Indianapolis, Indiana, United States).

Some of these data have been published in abstract form: American Diabetes Association $68^{\text {th }}$ Scientific Sessions, June 6-10, 2008, San Francisco, California, United States.

ClinicalTrials.gov identifier: NCT00382239

Conflict of interest: T. Kadowaki has participated in advisory top 10 countries predicted to have the greatest numbers of people with diabetes in the year 2030 (8.9 million) [1]. The combination of Westernized lifestyle

boards for Novo Nordisk, Novartis, and Eli Lilly and Company; has received consulting fees from Novo Nordisk, Novartis, and Merck; and has received financial support or grants to conduct research from Novo Nordisk and Eli Lilly and Company. M. Namba has participated in advisory boards for Novo Nordisk and Novartis; has received consulting fees from Novo Nordisk; and has received financial support or grants to conduct research from Novo Nordisk, Eli Lilly and Company, and Banyu Pharmaceutical Company, Ltd. A. Yamamura and H. Sowa are employees and shareholders of Eli Lilly and Company (Kobe, Japan). A. M. Wolka and R. G. Brodows are employees and shareholders of Eli Lilly and Company (Indianapolis, Indiana, United States). 
changes with the Japanese 'thrifty' genotype, which can contribute to imbalances in energy expenditure, glucose homeostasis, and glucose disposal efficiency in modernized societies, have been implicated in the increasing prevalence of diabetes in Japan [2-4], despite a low prevalence of obesity compared with Western societies [5].

Development of pharmacological therapies with novel mechanisms of action is of clinical interest for the treatment of Japanese patients with type 2 diabetes. Exenatide is the first in a class of antidiabetic agents known as the glucagon-like peptide-1 (GLP-1) receptor agonists. Exenatide shares several metabolic effects with the naturally occurring human incretin gut hormone GLP-1, including glucose-dependent enhancement of insulin secretion, suppression of elevated glucagon secretion, slowing of gastric emptying, and enhancement of satiety $[6,7]$.

A randomized, single-blind, placebo-controlled, parallel study has previously evaluated the pharmacokinetics, pharmacodynamics, tolerability, and safety of $2.5 \mu \mathrm{g}, 5 \mu \mathrm{g}, 10 \mu \mathrm{g}$, and $15 \mu \mathrm{g}$ exenatide over a period of 10 days in a group of 40 Japanese inpatients with type 2 diabetes being treated with either diet and exercise alone or oral antidiabetic agents [8]. This study showed that, at doses up to $10 \mu \mathrm{g}$, exenatide dose-dependently reduced plasma glucose and was generally well tolerated. The highest dose of exenatide, $15 \mu \mathrm{g}$, was poorly tolerated due to nausea and vomiting [8].

The current randomized, partial double-blind, placebo-controlled, parallel study, conducted over a period of 12 weeks in 153 Japanese patients whose type 2 diabetes was suboptimally controlled despite therapeutic doses of oral antidiabetic agent(s), was designed to further evaluate the dose-dependent effects on glycemic control and safety of $2.5 \mu \mathrm{g}, 5 \mu \mathrm{g}$, and 10 $\mu \mathrm{g}$ exenatide.

\section{Patients and Methods}

\section{Patients}

Japanese patients were included if they were between 20 and 75 years of age and had type 2 diabetes and a body weight $\geq 50 \mathrm{~kg}$. Patients were required to have been managing their type 2 diabetes with therapeutic doses of a sulfonylurea (SU) alone, SU plus a biguanide (BG), or SU plus a thiazolidinedione (TZD) for at least 3 months prior to screening. Patients using an $\alpha$-glucosidase inhibitor $(\alpha$-GI) or a meglitinide derivative could be included in this study, but were required to discontinue these oral antidiabetic agents prior to initiation of study drug. Despite taking therapeutic doses of oral antidiabetic agent(s), patients were required to have suboptimal glycemic control, as evidenced by a hemoglobin $\mathrm{A} 1 \mathrm{c}(\mathrm{HbA} 1 \mathrm{c})$ ranging from $7 \%$ to $10 \%$ for patients treated with SU alone, SU plus a BG, or SU plus a TZD, or from $6.5 \%$ to $9.5 \%$ for patients treated with an $\alpha$-GI or a meglitinide derivative.

Exclusion criteria included treatment with any exogenous insulin or drug directly affecting gastrointestinal motility within the 3 months prior to screening; clinically significant renal or hepatic disease; blood pressure $\geq 160 / 100 \mathrm{mmHg}$; hospitalization for cardiac disease within the year prior to inclusion in the study; clinically significant history of or active digestive disease within the year prior to inclusion in the study; active or untreated malignancy or remission from clinically significant malignancy for $<5$ years; obvious hyperglycemia as evidenced by self-monitored blood glucose $\geq 250 \mathrm{mg} / \mathrm{dL}$ in the fasting state or $\geq 350 \mathrm{mg} /$ $\mathrm{dL}$ measured at any time; or $>1$ severe hypoglycemic episode requiring the assistance of another person within the 3 months prior to screening. Female patients of childbearing age were excluded if they were pregnant at the time of enrollment, intended to become pregnant during the study, had not practiced a reliable method of birth control for the 3 months prior to screening, or did not agree to continue practicing a reliable method of birth control during the study.

\section{Study design}

This was a 12 -week, phase 2, randomized, placebo-controlled, parallel study conducted at 20 centers in Japan. Patients, investigators, and the sponsor were unblinded to the injection volume but blinded to the distinction between exenatide and placebo. After screening, $\alpha$-GI and meglitinide derivatives had to be discontinued and washed out for a period of 2 to 3 weeks.

Patients were randomly assigned to subcutaneous injections of placebo $(\mathrm{N}=40), 2.5 \mu \mathrm{g}$ exenatide $(\mathrm{N}=$ 38), $5 \mu$ g exenatide $(\mathrm{N}=37)$, or $10 \mu$ g exenatide $(\mathrm{N}=$ 38) twice daily using a dynamic allocation algorithm that involved allocation factors including $\mathrm{HbA} 1 \mathrm{c}$ val- 
ue $(<8.5 \%$ or $\geq 8.5 \%)$ and prior use of an $\alpha$-GI or meglitinide derivative. Patients randomly assigned to 10 $\mu \mathrm{g}$ exenatide received $5 \mu \mathrm{g}$ twice daily for the first 4 weeks, with the dose escalated to $10 \mu \mathrm{g}$ twice daily for the final 8 weeks. Patients self-administered study drug subcutaneously in the abdomen 15 minutes before the morning and evening meals, with an allowance of 0 to 60 minutes. SU could be discontinued or the dose reduced, at the discretion of the investigator, in the event of a documented hypoglycemic episode (self-monitored blood glucose $<70 \mathrm{mg} / \mathrm{dL}$ at the onset of hypoglycemic symptoms).

Institutional review boards provided written approval of the study protocol and the informed consent document. The study was conducted in accordance with the ethical principles of the Declaration of Helsinki and was consistent with good clinical practices and applicable laws and regulations. Investigators obtained written informed consent from patients prior to administering study drug or performing protocol procedures.

\section{Study end points}

The primary end point was change in $\mathrm{HbAlc}$ from baseline to endpoint. Secondary end points included the percentage of patients achieving $\mathrm{HbA} 1 \mathrm{c}<7 \%$ at endpoint, fasting plasma glucose, body weight, serum lipids (total cholesterol, high- and low-density lipoprotein cholesterol, and triglycerides), and safety. Safety measures included treatment-emergent adverse events including hypoglycemia, amylase levels, and antibodies to exenatide. Investigators evaluated the intensity of treatment-emergent adverse events according to the following criteria: mild: the event was generally transient and did not interfere with the patient's daily activities; moderate: the event did not completely interrupt the patient's daily activities but caused him or her considerable discomfort; and severe: the event completely interrupted the patient's daily activities.

Assays

Clinical blood samples were analyzed by BML, Inc. (Tokyo, Japan) or Millipore Corp. (St. Charles, Missouri, United States). Antibodies to exenatide were measured using a solid-phase enzyme-linked immunosorbent assay as previously described [9].

\section{Statistical analyses}

Sample size was determined based on the results from previous clinical studies performed in the United States [10-13]. A sample size of at least 33 patients per treatment group was needed to ensure power exceeding $90 \%$ to detect a significant difference between the $10 \mu \mathrm{g}$ exenatide and placebo treatment groups by Williams' test, with a one-sided significance level of $2.5 \%$. Considering differences between the patient population in the current Japanese study vs. the previous studies conducted in the United States, the target number of patients per treatment group was 35 .

The primary efficacy measure was change in $\mathrm{HbA1c}$ from baseline to endpoint. Endpoint was defined as week 12 for patients who completed the study or the last observation carried forward for patients who discontinued early. The primary efficacy analysis was based on Williams' test to identify the minimal dose of exenatide that yielded a significant difference in $\mathrm{HbAlc}$ vs. placebo, assuming a monotonicity of the dose-response relationship with regard to the mean change in HbAlc over the dose range of $0 \mu \mathrm{g}$ (placebo) to $10 \mu$ g exenatide. The analysis was performed in the order of the $10 \mu \mathrm{g}, 5 \mu \mathrm{g}$, and $2.5 \mu \mathrm{g}$ exenatide treatment groups until a significant difference was no longer detected. A one-sided significance level of 2.5\% was used in these statistical analyses.

Data are presented for the full analysis set, which includes all randomized patients who received at least one dose of study drug and who had post-baseline data available. All tests of treatment effects were conducted at a two-sided significance level of 5\%, unless otherwise stated. Unless otherwise stated, data are presented as means \pm standard errors.

\section{Results}

\section{Patient disposition and baseline characteristics}

Patient disposition is shown in Table 1. Of 153 randomized patients, 151 were included in the full analysis set. Two patients withdrew their consent and did not receive study drug. Overall, 90.7\% (137/151) of patients in the full analysis set completed the study.

Patients in the full analysis set were generally balanced among treatment groups with respect to baseline characteristics (Table 1). Using a two-sided sig- 
Table 1. Patient disposition and baseline characteristics

\begin{tabular}{|c|c|c|c|c|c|}
\hline & Placebo & $2.5 \mu \mathrm{g}$ exenatide & $5 \mu \mathrm{g}$ exenatide & $10 \mu \mathrm{g}$ exenatide & \\
\hline \multicolumn{6}{|l|}{ Patient disposition } \\
\hline All randomized & 40 & 38 & 37 & 38 & \\
\hline Full analysis set & 40 & $37^{\mathrm{a}}$ & 37 & $37^{\mathrm{a}}$ & \\
\hline Completed $^{\mathrm{b}}$ & $39(97.5)$ & $34(91.9)$ & $33(89.2)$ & $31(83.8)$ & \\
\hline 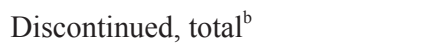 & $1(2.5)$ & $3(8.1)$ & $4(10.8)$ & $6(16.2)$ & \\
\hline Due to adverse event & $1(2.5)$ & $3(8.1)$ & $4(10.8)$ & $5(13.5)$ & \\
\hline Due to protocol violation & $0(0)$ & $0(0)$ & $0(0)$ & $1(2.7)$ & \\
\hline Baseline characteristics $^{\mathrm{b}}$ & $\mathrm{N}=40$ & $\mathrm{~N}=37$ & $\mathrm{~N}=37$ & $\mathrm{~N}=37$ & $p^{\mathrm{c}}$ \\
\hline Gender (\% male) & $30(75.0)$ & $26(70.3)$ & $25(67.6)$ & $23(62.2)$ & 0.673 \\
\hline Age (years) & $60.5 \pm 10.2$ & $62.2 \pm 7.8$ & $60.7 \pm 9.8$ & $57.8 \pm 10.4$ & 0.262 \\
\hline Weight (kg) & $71.1 \pm 14.0$ & $64.9 \pm 11.6$ & $65.6 \pm 9.8$ & $70.3 \pm 15.9$ & 0.087 \\
\hline Body mass index $\left(\mathrm{kg} / \mathrm{m}^{2}\right)$ & $25.8 \pm 4.6$ & $24.2 \pm 3.3$ & $25.0 \pm 3.4$ & $26.1 \pm 5.3$ & 0.191 \\
\hline Duration of type 2 diabetes (years) & $11.9 \pm 6.0$ & $14.8 \pm 10.9$ & $11.3 \pm 6.4$ & $9.6 \pm 6.0$ & 0.032 \\
\hline HbAlc $(\%)$ & $8.1 \pm 0.7$ & $8.0 \pm 0.8$ & $7.9 \pm 0.8$ & $7.9 \pm 0.9$ & 0.783 \\
\hline Fasting plasma glucose $(\mathrm{mg} / \mathrm{dL})$ & $161 \pm 36.7$ & $169 \pm 41.4$ & $164 \pm 33.4$ & $168 \pm 37.2$ & 0.799 \\
\hline \multicolumn{6}{|l|}{ Oral antidiabetic agent(s) } \\
\hline SU alone & $4(10.0)$ & $3(8.1)$ & $2(5.4)$ & $3(8.1)$ & ---- \\
\hline $\mathrm{SU}+\alpha-\mathrm{GI}$ & $0(0.0)$ & $4(10.8)$ & $2(5.4)$ & $1(2.7)$ & ---- \\
\hline $\mathrm{SU}+\mathrm{BG}$ & $18(45.0)$ & $17(45.9)$ & $18(48.6)$ & $18(48.6)$ & ---- \\
\hline $\mathrm{SU}+\mathrm{BG}+\alpha-\mathrm{GI}$ & $9(22.5)$ & $4(10.8)$ & $8(21.6)$ & $7(18.9)$ & ---- \\
\hline $\begin{array}{l}\mathrm{SU}+\mathrm{BG}+ \\
\text { meglitinide derivative }\end{array}$ & $0(0.0)$ & $0(0.0)$ & $2(5.4)$ & $1(2.7)$ & ---- \\
\hline $\mathrm{SU}+\mathrm{TZD}$ & $4(10.0)$ & $3(8.1)$ & $4(10.8)$ & $2(5.4)$ & ---- \\
\hline $\mathrm{SU}+\mathrm{TZD}+\alpha-\mathrm{GI}$ & $5(12.5)$ & $6(16.2)$ & $1(2.7)$ & $5(13.5)$ & ---- \\
\hline Total cholesterol (mg/dL) & $203 \pm 26.6$ & $209 \pm 30.2$ & $200 \pm 36.0$ & $207 \pm 36.8$ & 0.666 \\
\hline HDL cholesterol (mg/dL) & $50 \pm 9.4$ & $55 \pm 13.1$ & $53 \pm 12.4$ & $55 \pm 12.0$ & 0.201 \\
\hline LDL cholesterol (mg/dL) & $121 \pm 24.2$ & $126 \pm 25.4$ & $117 \pm 29.1$ & $115 \pm 25.7$ & 0.250 \\
\hline Triglycerides (mg/dL) & $162 \pm 131.4$ & $131 \pm 119.7$ & $160 \pm 112.0$ & $190 \pm 257.1$ & 0.496 \\
\hline
\end{tabular}

Data are N (\%) or means \pm standard deviations. ${ }^{a}$ One patient randomized to this group discontinued prior to receiving study drug and was excluded from the full analysis set. ${ }^{b}$ Data are for the full analysis set. ${ }^{c} p$ for comparison among the treatment groups (chi-square test for categorical variables or one-way ANOVA for continuous variables). $\alpha$-GI $=\alpha$-glucosidase inhibitor. $\mathrm{ANOVA}=$ analysis of variance. $\mathrm{BG}=$ biguanide. $\mathrm{HbA1c}=$ hemoglobin $\mathrm{A} 1 \mathrm{c} . \mathrm{HDL}=$ high-density lipoprotein. $\mathrm{LDL}=$ low-density lipoprotein. $\mathrm{SU}=$ sulfonylurea. $\mathrm{TZD}=$ thiazolidinedione.

nificance level of $15 \%$, significant differences among the treatment groups were observed for duration of type 2 diabetes $(p=0.032)$ and body weight $(p=0.087)$ at baseline (one-way analysis of variance [ANOVA]). These differences would not be expected to affect the primary efficacy evaluation.

\section{Glycemic control}

A reduction from baseline in $\mathrm{HbAlc}$ was apparent by week 4 for all exenatide treatment groups, but not placebo (Figure 1A). HbA1c values decreased progressively in a dose-dependent manner over 12 weeks for all exenatide treatment groups, but remained essentially unchanged over the same period for placebo (Figure 1A).

HbA1c changes from baseline to endpoint were $-0.9 \pm 0.1 \%(p<0.001),-1.2 \pm 0.1 \%(p<0.001)$, and $-1.4 \pm 0.1 \%(p<0.001)$ for the $2.5 \mu \mathrm{g}, 5 \mu \mathrm{g}$, and 10 $\mu \mathrm{g}$ exenatide treatment groups, respectively, compared with $+0.02 \pm 0.1 \%$ for placebo (exenatide vs. placebo, Williams' test).

Of patients who had $\mathrm{HbA} 1 \mathrm{c} \geq 7.0 \%$ at baseline, $50.0 \%(16 / 32), 71.4 \%(25 / 35)$, and $79.4 \%(27 / 34)$ in the $2.5 \mu \mathrm{g}, 5 \mu \mathrm{g}$, and $10 \mu \mathrm{g}$ exenatide treatment groups achieved $\mathrm{HbA} 1 \mathrm{c}<7.0 \%$ at endpoint, compared with 


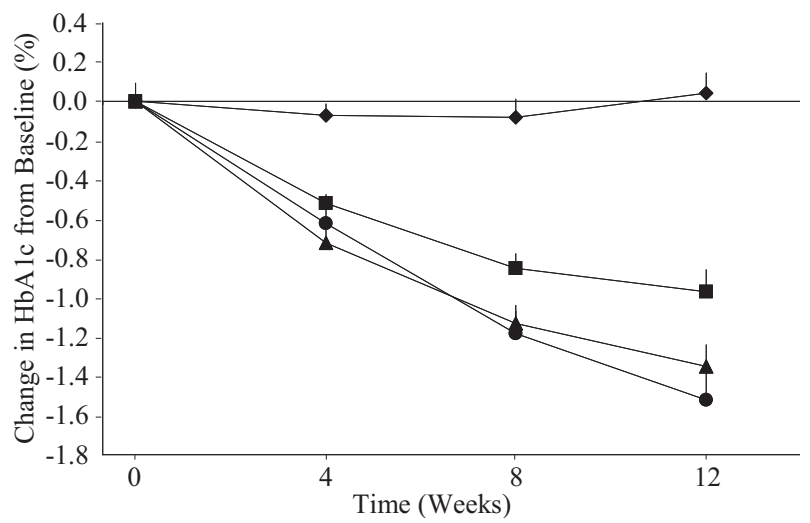

Figure 1A. Change in $\mathrm{HbAlc}$ from baseline over time. Data are means \pm standard errors for the full analysis set. placebo; $\mathbf{\square}: 2.5 \mu \mathrm{g}$ exenatide; $\mathbf{\Delta}: 5 \mu \mathrm{g}$ exenatide; $\bullet$ : $10 \mu$ g exenatide

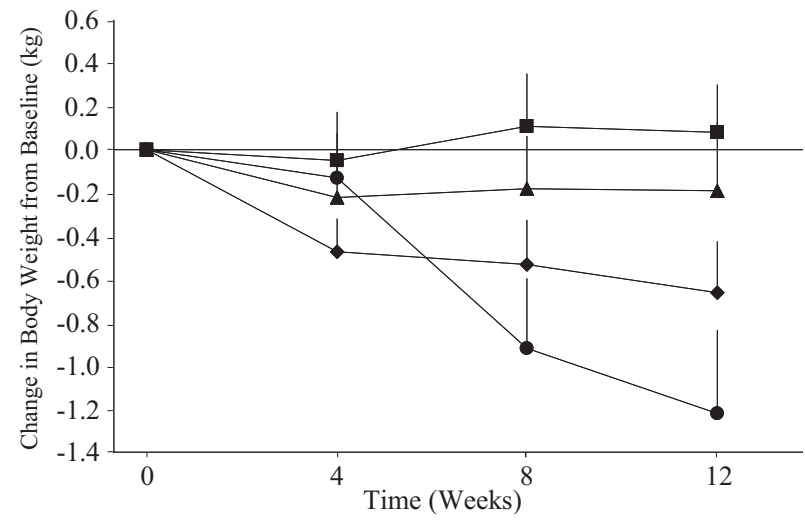

Figure 2. Change in body weight from baseline over time. Data are means \pm standard errors for the full analysis set. $\downarrow$ : placebo; $\mathbf{\square}: 2.5 \mu \mathrm{g}$ exenatide; $\boldsymbol{\Delta}: 5 \mu \mathrm{g}$ exenatide; $\bullet: 10$ $\mu \mathrm{g}$ exenatide

$5.1 \%(2 / 39)$ for placebo $(p<0.001$, Cochran-Armitage trend test) (Figure 1B).

A significant difference among the treatment groups was observed for change in fasting plasma glucose from baseline to endpoint ( $p<0.001$, one-way ANOVA). Fasting plasma glucose changes from baseline to endpoint were $-18.6 \pm 5.7 \mathrm{mg} / \mathrm{dL}(p=0.001)$, $-25.0 \pm 7.0 \mathrm{mg} / \mathrm{dL}(p<0.001)$, and $-28.9 \pm 5.9 \mathrm{mg} /$ $\mathrm{dL}(p<0.001)$ for the $2.5 \mu \mathrm{g}, 5 \mu \mathrm{g}$, and $10 \mu \mathrm{g}$ exenatide treatment groups, respectively, compared with $+6.0 \pm 4.8 \mathrm{mg} / \mathrm{dL}$ for placebo (exenatide vs. placebo, Student's t test).

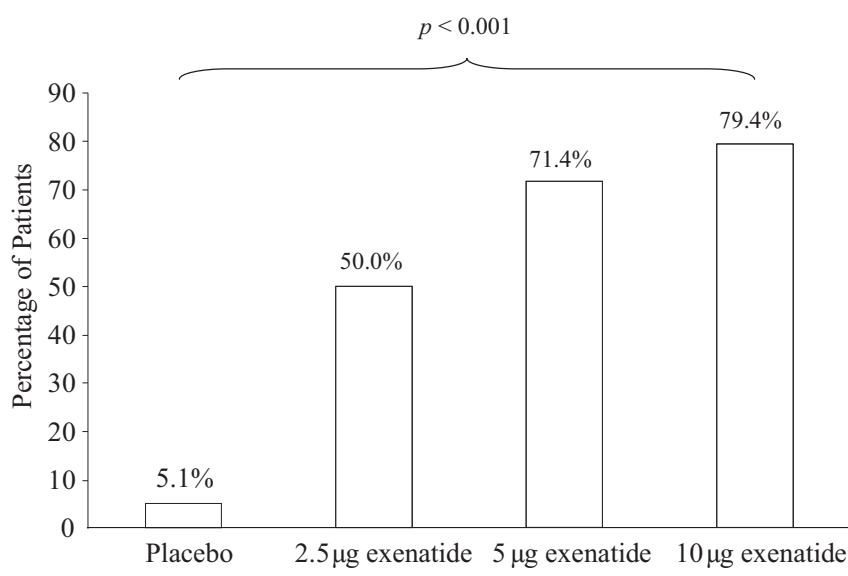

Figure 1B. Percentage of patients with baseline $\mathrm{HbA} 1 \mathrm{c} \geq 7.0 \%$ who achieved $\mathrm{HbA} 1 \mathrm{c}<7.0 \%$ at endpoint.

\section{$S U$ dose reduction or discontinuation and $\mathrm{HbAlc}$}

An SU dose reduction or discontinuation following a documented hypoglycemic episode was performed for $2.5 \%$ (1/40), $2.7 \%$ (1/37), 27.0\% (10/37), and $48.6 \%(18 / 37)$ of patients treated with placebo, $2.5 \mu \mathrm{g}, 5 \mu \mathrm{g}$, and $10 \mu \mathrm{g}$ exenatide, respectively. Discontinuations (as opposed to dose reductions only) accounted for no patients treated with placebo or 2.5 $\mu \mathrm{g}$ exenatide, 2 of the 10 patients treated with $5 \mu \mathrm{g}$ exenatide, and 5 of the 18 patients treated with $10 \mu \mathrm{g}$ exenatide.

In the $5 \mu \mathrm{g}$ exenatide group, the reduction in $\mathrm{HbA} 1 \mathrm{c}$ from baseline to endpoint was $-1.1 \pm 0.2 \%$ for patients with an SU dose reduction or discontinuation vs. $-1.3 \pm 0.1 \%$ for patients without an SU dose reduction or discontinuation. In the $10 \mu \mathrm{g}$ exenatide group, the reduction in $\mathrm{HbAlc}$ from baseline to endpoint was $-1.2 \pm 0.2 \%$ for patients with an SU dose reduction or discontinuation vs. $-1.6 \pm 0.2 \%$ for patients without an SU dose reduction or discontinuation.

\section{Body weight}

The greatest reduction in body weight after 12 weeks was observed for the $10 \mu \mathrm{g}$ exenatide treatment group, followed by placebo and then $5 \mu \mathrm{g}$ exenatide. Body weight remained essentially unchanged from baseline to 12 weeks for the $2.5 \mu \mathrm{g}$ exenatide treatment group (Figure 2). 
Table 2. Change in serum lipids from baseline to endpoint

\begin{tabular}{|c|c|c|c|c|c|}
\hline & $\begin{array}{l}\text { Placebo } \\
\mathrm{N}=40\end{array}$ & $\begin{array}{c}2.5 \mu g \text { exenatide } \\
\mathrm{N}=37\end{array}$ & $\begin{array}{c}5 \mu \text { g exenatide } \\
\mathrm{N}=37\end{array}$ & $\begin{array}{c}10 \mu \mathrm{g} \text { exenatide } \\
\mathrm{N}=37\end{array}$ & $p^{\mathrm{a}}$ \\
\hline $\begin{array}{l}\text { Total cholesterol } \\
(\mathrm{mg} / \mathrm{dL})\end{array}$ & $+1.7 \pm 2.8$ & $-4.0 \pm 4.4$ & $-9.3 \pm 4.2^{b}$ & $-15.7 \pm 5.4^{b}$ & 0.029 \\
\hline $\begin{array}{l}\text { HDL cholesterol } \\
(\mathrm{mg} / \mathrm{dL})\end{array}$ & $+0.8 \pm 0.9$ & $-3.4 \pm 1.0^{\mathrm{c}}$ & $-3.7 \pm 1.2^{c}$ & $-5.7 \pm 1.4^{c}$ & $<0.001$ \\
\hline $\begin{array}{l}\text { LDL cholesterol } \\
(\mathrm{mg} / \mathrm{dL})\end{array}$ & $+0.8 \pm 2.8$ & $-4.3 \pm 3.9$ & $-4.4 \pm 3.3$ & $-1.3 \pm 3.6$ & 0.651 \\
\hline $\begin{array}{l}\text { Triglycerides } \\
(\mathrm{mg} / \mathrm{dL})\end{array}$ & $-24.5 \pm 17.8$ & $-0.4 \pm 16.4$ & $-32.5 \pm 14.5$ & $-61.9 \pm 34.9$ & 0.292 \\
\hline
\end{tabular}

Data are means \pm standard errors for the full analysis set. ${ }^{a} p$ for comparison among the treatment groups (one-way ANOVA). ${ }^{\mathrm{b}}$ Significant difference between exenatide and placebo (both $p \leq 0.031$, Student's $\mathrm{t}$ test). ${ }^{\mathrm{c}}$ Significant difference between exenatide and placebo (all $p \leq 0.003$, Student's t test). ANOVA = analysis of variance. HDL $=$ high-density lipoprotein. LDL $=$ low-density lipoprotein.

Table 3. Treatment-emergent adverse events reported in $\geq 10 \%$ of patients in any treatment group

\begin{tabular}{|c|c|c|c|c|c|}
\hline MedDRA-preferred term & $\begin{array}{l}\text { Placebo } \\
\mathrm{N}=40\end{array}$ & $\begin{array}{c}2.5 \mu \mathrm{g} \text { exenatide } \\
\mathrm{N}=37\end{array}$ & $\begin{array}{c}5 \mu \mathrm{g} \text { exenatide } \\
\mathrm{N}=37\end{array}$ & $\begin{array}{c}10 \mu \mathrm{g} \text { exenatide } \\
\mathrm{N}=37\end{array}$ & $p^{\mathrm{a}}$ \\
\hline Nausea & $0(0.0)$ & $4(10.8)$ & $3(8.1)$ & $13(35.1)$ & $<0.001$ \\
\hline Vomiting & $0(0.0)$ & $2(5.4)$ & $5(13.5)$ & $3(8.1)$ & 0.067 \\
\hline Constipation & $2(5.0)$ & $4(10.8)$ & $4(10.8)$ & $3(8.1)$ & 0.627 \\
\hline Diarrhea & $0(0.0)$ & $1(2.7)$ & $4(10.8)$ & $3(8.1)$ & 0.044 \\
\hline Stomach discomfort & $1(2.5)$ & $2(5.4)$ & $4(10.8)$ & $3(8.1)$ & 0.212 \\
\hline Abdominal distention & $0(0.0)$ & $0(0.0)$ & $4(10.8)$ & $2(5.4)$ & 0.055 \\
\hline Anorexia & $0(0.0)$ & $0(0.0)$ & $1(2.7)$ & $5(13.5)$ & 0.002 \\
\hline Decreased appetite & $0(0.0)$ & $0(0.0)$ & $3(8.1)$ & $5(13.5)$ & 0.003 \\
\hline Nasopharyngitis & $11(27.5)$ & $9(24.3)$ & $3(8.1)$ & 7 (18.9) & 0.142 \\
\hline Blood glucose decreased & $4(10.0)$ & $3(8.1)$ & $8(21.6)$ & $8(21.6)$ & 0.065 \\
\hline Hypoglycemia & $4(10.0)$ & $10(27.0)$ & $16(43.2)$ & $20(54.1)$ & $<0.001$ \\
\hline
\end{tabular}

Data are N (\%) for the full analysis set. ${ }^{a} p$ for Cochran-Armitage trend test. MedDRA = Medical Dictionary for Regulatory Activities.

A significant difference among the treatment groups was observed for change in body weight from baseline to endpoint ( $\mathrm{p}=0.004$, one-way ANOVA). Body weight changes from baseline to endpoint were +0.08 $\pm 0.2 \mathrm{~kg}(\mathrm{p}=0.018),-0.2 \pm 0.3 \mathrm{~kg}(\mathrm{p}=0.224)$, and $-1.3 \pm 0.3 \mathrm{~kg}(\mathrm{p}=0.148)$ for the $2.5 \mu \mathrm{g}, 5 \mu \mathrm{g}$, and 10 $\mu \mathrm{g}$ exenatide treatment groups, respectively, compared with $-0.7 \pm 0.2 \mathrm{~kg}$ for placebo (exenatide vs. placebo, Student's t test).

\section{Serum lipids}

Table 2 shows the change in serum lipids from baseline to endpoint. A significant difference among the treatment groups was observed for change in total cholesterol $(p=0.029)$ and change in high-density lipoprotein cholesterol $(p<0.001)$ from baseline to endpoint (one-way ANOVA). Reductions in total cho- lesterol were significantly greater for $5 \mu$ g exenatide $(p$ $=0.031)$ and $10 \mu \mathrm{g}$ exenatide $(p=0.005)$ vs. placebo (Student's $t$ test). Also, reductions in high-density lipoprotein cholesterol were significantly greater for 2.5 $\mu \mathrm{g}$ exenatide $(p=0.002), 5 \mu \mathrm{g}$ exenatide $(p=0.003)$, and $10 \mu$ g exenatide $(p<0.001)$ vs. placebo (Student's $t$ test). No significant differences were observed between exenatide and placebo or among the treatment groups for changes in low-density lipoprotein cholesterol or triglycerides from baseline to endpoint.

\section{Adverse events and hypoglycemia}

Overall, $81.5 \%(123 / 151)$ of patients reported $\geq 1$ treatment-emergent adverse event (placebo: $65.0 \%$ [26/40]; $2.5 \mu \mathrm{g}$ exenatide: 78.4\% [29/37]; $5 \mu \mathrm{g}$ exenatide: $89.2 \%$ [33/37]; and $10 \mu \mathrm{g}$ exenatide: $94.6 \%$ [35/37]). A dose-dependent increase was observed for 
the overall incidence of treatment-emergent adverse events ( $p<0.001$, Cochran-Armitage trend test).

For $83.7 \%(103 / 123)$ of patients who had $\geq 1$ treatment-emergent adverse event, the maximum severity of the event(s) was mild, in the opinion of the investigators; for $99.2 \%$ (122/123), the maximum severity of the event(s) was either mild or moderate. One serious adverse event (tendon rupture) was reported for a patient in the $2.5 \mu \mathrm{g}$ exenatide group. The event was considered severe and unrelated to study drug, in the opinion of the investigator. No deaths occurred during the study.

Treatment-emergent adverse events reported by $\geq 10 \%$ of patients in any treatment group are shown in Table 3. Of these treatment-emergent adverse events, dose-dependent increases in incidence were observed for hypoglycemia, nausea, anorexia, decreased appetite, and diarrhea (all $p \leq 0.044$, Cochran-Armitage trend test).

Ten percent (4/40), 27.0\% (10/37), 43.2\% (16/37), and $54.1 \%(20 / 37)$ of patients in the placebo, $2.5 \mu \mathrm{g}$ exenatide, $5 \mu \mathrm{g}$ exenatide, and $10 \mu \mathrm{g}$ exenatide groups reported hypoglycemia during the study. All of these patients reported hypoglycemia that was considered mild, in the opinion of the investigators, with the exception of one patient in the $5 \mu \mathrm{g}$ exenatide treatment group who reported moderate hypoglycemia. No severe hypoglycemia occurred during the study.

\section{Amylase levels and pancreatitis}

Baseline-to-endpoint changes in amylase were not clinically relevant, and mean values were within the normal range for all groups at endpoint (placebo: $+5 \pm$ $3 \mathrm{U} / \mathrm{L}, 101 \pm 6 \mathrm{U} / \mathrm{L}$ at endpoint; $2.5 \mu \mathrm{g}$ exenatide: +7 $\pm 3 \mathrm{U} / \mathrm{L}, 111 \pm 6 \mathrm{U} / \mathrm{L}$ at endpoint; $5 \mu \mathrm{g}$ exenatide: $+3 \pm$ $2 \mathrm{U} / \mathrm{L}, 103 \pm 7 \mathrm{U} / \mathrm{L}$ at endpoint; and $10 \mu$ g exenatide: $+6 \pm 4 \mathrm{U} / \mathrm{L} ; 100 \pm 5 \mathrm{U} / \mathrm{L}$ at endpoint). No treatmentemergent pancreatitis was reported during the study.

\section{Antibodies to exenatide}

At endpoint, 51.4\% (19/37), 29.7\% (11/37), and $51.4 \%(19 / 37)$ of patients in the $2.5 \mu \mathrm{g}, 5 \mu \mathrm{g}$, and 10 $\mu \mathrm{g}$ exenatide treatment groups, respectively, had detectable antibodies to exenatide ( $\geq 1 / 25$ dilution). The presence of antibodies to exenatide had no clinically relevant effect on glycemic control or safety (data not shown).

\section{Discussion}

Over 12 weeks, exenatide improved $\mathrm{HbA} 1 \mathrm{c}$ and fasting plasma glucose in Japanese patients whose type 2 diabetes was suboptimally controlled despite therapeutic doses of oral antidiabetic agent(s). Significant dose-dependent responses were observed for doses ranging from $2.5 \mu \mathrm{g}$ to $10 \mu \mathrm{g}$.

Patients in the current study had type 2 diabetes on average for 10 to 15 years, with mean $\mathrm{HbAlc}$ values at baseline of $7.9 \%$ to $8.1 \%$, indicating a moderately advanced stage of type 2 diabetes. The reductions in HbAlc $(-0.9 \%,-1.2 \%$, and $-1.4 \%)$ and fasting plasma glucose $(-18.6 \mathrm{mg} / \mathrm{dL},-25.0 \mathrm{mg} / \mathrm{dL}$, and $-28.9 \mathrm{mg} / \mathrm{dL})$ observed from baseline to endpoint for the $2.5 \mu \mathrm{g}, 5$ $\mu \mathrm{g}$, and $10 \mu \mathrm{g}$ exenatide treatment groups, respectively, were dose-dependent and also clinically relevant for all exenatide treatment groups. When evaluating effects on glycemic control, it is valuable to ascertain the proportion of patients who achieved a target $\mathrm{HbAlc}$. In this study, exenatide dose-dependently enabled a greater proportion of patients $(50.0 \%$ to $79.4 \%$ ) to achieve an $\mathrm{HbA} 1 \mathrm{c}$ value of $<7.0 \%$ at endpoint than did placebo $(5.1 \%)$. The positive effects of exenatide on glycemic control in Japanese patients with type 2 diabetes are consistent with those from previous placebo-controlled studies evaluating $5 \mu \mathrm{g}$ and $10 \mu \mathrm{g}$ exenatide combined with oral antidiabetic agents in predominantly Caucasian populations [10$12,14]$.

In this group of Japanese patients, who had mean body weights of 65 to $71 \mathrm{~kg}$ at baseline, exenatide appeared to have a neutral effect on body weight, as compared with placebo, during the study. This apparent neutral effect of exenatide on body weight is notable since other antidiabetic therapies, including SU, TZDs, and insulins, can cause weight gain in patients with type 2 diabetes [15]. The reasons for the unexpected weight loss $(-0.7 \mathrm{~kg})$ with placebo observed in this study are not known. Body weight reductions of -0.9 to $-2.2 \mathrm{~kg}$ have been observed with exenatide during previous placebo-controlled studies of $5 \mu \mathrm{g}$ and 10 $\mu \mathrm{g}$ exenatide combined with oral antidiabetic agents $[10-12,14]$. However, patients who participated in these previous studies were primarily Caucasian rather than Japanese and had greater baseline body mass indexes ( 33 to $34 \mathrm{~kg} / \mathrm{m}^{2}$ ), on average, than patients in the current study $\left(25 \mathrm{~kg} / \mathrm{m}^{2}\right)$.

The prevention of diabetic complications requires 
control of factors other than glycemia, including lipid profiles. A prospective cohort study of 4014 elderly Japanese patients with type 2 diabetes has shown that tight lipid control reduces the incidence of vascular events in this population [16]. Previous placebo-controlled studies have shown that exenatide combined with oral antidiabetic agents has a neutral effect on serum lipids over the short term in predominantly Caucasian populations $[10,11,14]$. In this study of Japanese patients, clinically relevant reductions in total cholesterol from baseline to endpoint were observed for the $5 \mu \mathrm{g}(-9.3 \mathrm{mg} / \mathrm{dL})$ and $10 \mu \mathrm{g}(-15.7 \mathrm{mg} /$ $\mathrm{dL}$ ) exenatide treatment groups. Reductions in highdensity lipoprotein cholesterol with $2.5 \mu \mathrm{g}, 5 \mu \mathrm{g}$, and $10 \mu \mathrm{g}$ exenatide, despite being significantly greater than with placebo, were modest and the mean values remained in the normal range after 12 weeks. A large degree of variability in triglyceride levels was observed within the treatment groups, making these data difficult to interpret. Additional longer-term studies appear warranted to further evaluate the effects of exenatide on serum lipids in Japanese patients with type 2 diabetes.

The safety profile observed in this study was consistent with previous reports for GLP-1 agonists, for both Japanese and non-Japanese populations [8-14, 17-19]. Consistent with placebo-controlled studies of exenatide combined with oral antidiabetic agents performed in predominantly Caucasian populations $[10-12,14]$ and a study of exenatide performed in 40 Japanese inpatients with type 2 diabetes being treated with either diet and exercise alone or oral antidiabetic agents [8], the treatment-emergent adverse events reported in this study were primarily gastrointestinal in nature, with significant dose-dependent increases in the incidences of nausea, anorexia, decreased appetite, and diarrhea.

A significant dose-dependent increase in the incidence of hypoglycemia was also observed in the current study. Exenatide enhances insulin secretion from pancreatic $\beta$-cells in a glucose-dependent fashion, wherein insulin secretion decreases as glucose levels normalize $[6,7]$. This mechanism reduces exenatide's potential to cause hypoglycemia. However, up to $54.1 \%$ of exenatide-treated patients reported hypoglycemia during this study. This observation is likely because all patients were taking a concomitant SU, with or without additional concomitant oral agents (BG or TZD). In two previous placebo-controlled studies of exenatide combined with oral antidiabetic agents performed in predominantly Caucasian populations, concomitant SUs have been implicated in increasing the incidence of hypoglycemia when coupled with lower ambient glycemia and increasing exenatide dose $[10,12]$.

$\mathrm{SU}$ is the most common oral antidiabetic agent used as monotherapy in Japan, and is also frequently used concomitantly with other oral antidiabetic agents. During a cross-sectional study of 17,000 Japanese patients with diabetes, $37 \%$ to $43 \%$ of patients on oral therapy were taking an SU alone, and an additional $35 \%$ were taking an $\mathrm{SU}$ in combination with a $\mathrm{BG}$, an $\alpha$-GI, or a BG plus an $\alpha$-GI [20]. This prominent use of $\mathrm{SU}$ in Japanese patients is consistent with the pathology of the development of type 2 diabetes in this population, which has been characterized primarily by insufficient insulin secretion from pancreatic $\beta$-cells $[3,21]$.

A proactive approach to $\mathrm{SU}$ dose management has been suggested in order to reduce the incidence of hypoglycemia in exenatide-treated patients [12]. However, proactive SU dose adjustments were not performed in the current study because, according to the protocol, SU could be discontinued or the dose reduced only after a documented hypoglycemic episode. Dosing guidelines for the concomitant use of exenatide and SU in Japanese patients would be useful in clinical practice and should be devised.

Because of the potentially immunogenic properties of any protein or peptide pharmaceutical, antibodies to exenatide were measured. In the current study, the presence of antibodies to exenatide had no clinically relevant effects on glycemic control or safety in Japanese patients. Previous studies in predominantly Caucasian populations have demonstrated that antibody titers diminish over time in most patients [22]; longer-term studies would be required to evaluate antibody titers over time in Japanese patients.

This study has several limitations. First, the study design was partial double-blind, in that patients, investigators, and the sponsor were blinded to the distinction between exenatide and placebo, but unblinded to injection volume. A full double-blind design may have been more robust. Also, there were no standardized diet and exercise recommendations in the current study.

In conclusion, the data show that the effects of exenatide twice daily on glycemic control are similar for Japanese and Caucasian patients and furthermore 
support the use of exenatide at the maximal tolerable dose, up to $10 \mu \mathrm{g}$ twice daily, in the treatment of Japanese patients with type 2 diabetes. Additional studies of longer duration are required to further evaluate the efficacy and safety of exenatide in Japanese patients with type 2 diabetes.

\section{Acknowledgment}

This study was supported by Amylin Pharmaceuticals, Inc. (San Diego, California, United States) and Eli Lilly and Company (Indianapolis, Indiana, United States). Hirofumi Shigeta, MD, PhD (formerly of Eli Lilly Japan KK, Kobe, Japan), provided medical advice and support during the writing of this manuscript.

\section{References}

1. Wild S, Roglic G, Green A, Sicree R, King H (2004) Global prevalence of diabetes: estimates for the year 2000 and projections for 2030. Diabetes Care 27:10471053.

2. Kawamori R (2002) Diabetes trends in Japan. Diabetes Metab Res Rev 18 Suppl 3:S9-S13.

3. Hirose T, Kawamori R (2005) Diabetes in Japan. Curr Diab Rep 5:226-229.

4. Yazaki Y, Kadowaki T (2006) Combating diabetes and obesity in Japan. Nat Med 12:73-74.

5. Yoshiike N, Matsumura Y, Zaman MM, Yamaguchi M (1998) Descriptive epidemiology of body mass index in Japanese adults in a representative sample from the National Nutrition Survey 1990-1994. Int J Obes Relat Metab Disord 22:684-687.

6. Drucker DJ (2003) Enhancing incretin action for the treatment of type 2 diabetes. Diabetes Care 26:29292940.

7. Triplitt CL (2007) New technologies and therapies in the management of diabetes. Am J Manag Care 13 Suppl 2:S47-S54.

8. Kothare PA, Linnebjerg H, Isaka Y, Uenaka K, Yamamura A, Yeo KP, de la Pẽna A, Teng CH, Mace K, Fineman M, Shigeta H, Sakata Y, Irie S (2008) Pharmacokinetics, pharmacodynamics, tolerability, and safety of exenatide in Japanese patients with type 2 diabetes mellitus. J Clin Pharmacol 48:1389-1399.

9. Fineman MS, Bicsak TA, Shen LZ, Taylor K, Gaines E, Varns A, Kim D, Baron AD (2003) Effect on glycemic control of exenatide (synthetic exendin-4) additive to existing metformin and/or sulfonylurea treatment in patients with type 2 diabetes. Diabetes Care 26:23702377.

10. Buse JB, Henry RR, Han J, Kim DD, Fineman MS, Baron AD; Exenatide-113 Clinical Study Group (2004) Effects of exenatide (exendin-4) on glycemic control over 30 weeks in sulfonylurea-treated patients with type 2 diabetes. Diabetes Care 27:2628-2635.

11. DeFronzo RA, Ratner RE, Han J, Kim DD, Fineman MS, Baron AD (2005) Effects of exenatide (exendin-4) on glycemic control and weight over 30 weeks in met- formin-treated patients with type 2 diabetes. Diabetes Care 28:1092-1100.

12. Kendall DM, Riddle MC, Rosenstock J, Zhuang D, Kim DD, Fineman MS, Baron AD (2005) Effects of exenatide (exendin-4) on glycemic control over 30 weeks in patients with type 2 diabetes treated with metformin and a sulfonylurea. Diabetes Care 28:10831091.

13. Poon T, Nelson P, Shen L, Mihm M, Taylor K, Fineman M, Kim D (2005) Exenatide improves glycemic control and reduces body weight in subjects with type 2 diabetes: a dose-ranging study. Diabetes Technol Ther 7:467-477.

14. Zinman B, Hoogwerf BJ, Durán García S, Milton DR, Giaconia JM, Kim DD, Trautmann ME, Brodows RG (2007) The effect of adding exenatide to a thiazolidinedione in suboptimally controlled type 2 diabetes: a randomized trial. Ann Intern Med 146:477-485.

15. Riddle MC (2005) Glycemic management of type 2 diabetes: an emerging strategy with oral agents, insulins, and combinations. Endocrinol Metab Clin North Am 34:77-98.

16. Hayashi T, Kawashima S, Itoh H, Yamada N, Sone H, Watanabe H, Hattori Y, Ohrui T, Yoshizumi M, Yokote K, Kubota K, Nomura H, Umegaki H, Iguchi A; Japan CDM Group (2008) Importance of lipid levels in elderly diabetic individuals: baseline characteristics and 1-year survey of cardiovascular events. Circ J 72:218225.

17. Garber A, Henry R, Ratner R, Garcia-Hernandez PA, Rodriguez-Pattzi H, Olvera-Alvarez I, Hale PM, Zdravkovic M, Bode B; for the LEAD-3 (Mono) Study Group (2009) Liraglutide versus glimepiride monotherapy for type 2 diabetes (LEAD-3 Mono): a randomised, 52-week, phase III, double-blind, paralleltreatment trial. Lancet 373:473-481.

18. Nauck M, Frid A, Hermansen K, Shah NS, Tankova T, Mitha IH, Zdravkovic M, Düring M, Matthews DR; LEAD-2 Study Group (2009) Efficacy and safety comparison of liraglutide, glimepiride, and placebo, all in combination with metformin, in type 2 diabetes: 
the LEAD (liraglutide effect and action in diabetes)-2 study. Diabetes Care 32:84-90.

19. Seino Y, Rasmussen MF, Zdravkovic M, Kaku K (2008) Dose-dependent improvement in glycemia with oncedaily liraglutide without hypoglycemia or weight gain: a double-blind, randomized, controlled trial in Japanese patients with type 2 diabetes. Diabetes Res Clin Pract 81:161-168.

20. Kobayashi M, Yamazaki K, Hirao K, Oishi M, Kanatsuka A, Yamauchi M, Takagi H, Kawai K; Japan Diabetes Clinical Data Management Study Group (2006) The status of diabetes control and antidiabet- ic drug therapy in Japan - a cross-sectional survey of 17,000 patients with diabetes mellitus (JDDM 1). Diabetes Res Clin Pract 73:198-204.

21. Fukushima M, Usami M, Ikeda M, Nakai Y, Taniguchi A, Matsuura T, Suzuki H, Kurose T, Yamada Y, Seino $\mathrm{Y}$ (2004) Insulin secretion and insulin sensitivity at different stages of glucose tolerance: a cross-sectional study of Japanese type 2 diabetes. Metabolism 53:831835.

22. Byetta prescribing information. http://pi.lilly.com/us/ byetta-pi.pdf. Accessed June 8, 2009. 